\title{
The role of thrombospondins in wound healing, ischemia, and the foreign body reaction
}

\author{
Themis R. Kyriakides • Susan MacLauchlan
}

Received: 27 May 2009 / Accepted: 1 October 2009/Published online: 21 October 2009

(C) The Author(s) 2009. This article is published with open access at Springerlink.com

\begin{abstract}
Thrombospondin (TSP) 1 and TSP2 have been implicated in the regulation of several processes during tissue repair. Due to their matricellular nature, these proteins are thought to modulate cell-matrix interactions through a variety of mechanisms specific to the spatiotemporal context of their expression. Most notably, TSP1 and TSP2 appear to play distinct, non-overlapping roles in the healing of skin wounds. In contrast, both proteins have been implicated as regulators of ischemia-induced angiogenesis. Moreover, TSP2 has been shown to be a critical regulator of angiogenesis in the foreign body response (FBR). In this review, we discuss the role of TSPs in tissue repair and examine the mechanistic data regarding the ability of the thrombospondins to modulate cell-matrix interactions in this context.
\end{abstract}

Keywords Angiogenesis · Foreign body response ·

Ischemia $\cdot$ Thrombospondin $\cdot$ Wound healing

$\begin{array}{ll}\text { Abbreviations } \\ \text { cGMP } & \text { cyclic guanyl monophosphate } \\ \text { bFGF } & \text { basic fibroblast growth factor } \\ \text { ECs } & \text { endothelial cells } \\ \text { eNOS } & \text { endothelial nitric oxide synthase }\end{array}$

T. R. Kyriakides $\cdot$ S. MacLauchlan

Interdepartmental Program in Vascular Biology and Therapeutics and Departments of Pathology and Biomedical Engineering,

Yale University,

New Haven, CT 06519, USA

\section{T. R. Kyriakides $(\square)$}

Department of Pathology,

Yale University School of Medicine,

P.O. Box 208089, New Haven, CT 06520-8089, USA

e-mail: themis.kyriakides@yale.edu

$\begin{array}{ll}\text { ECM } & \text { extracellular matrix } \\ \text { FBR } & \text { foreign body response } \\ \text { FBGCs } & \text { foreign body giant cells } \\ \text { HUVECs } & \text { human umbilical vein endothelial cells } \\ \text { IAP } & \text { integrin associated protein } \\ \text { IL-1 } \beta & \text { interleukin } 1 \beta \\ \text { HSPGs } & \text { heparin sulfate proteoglycans } \\ \text { LAP } & \text { latency associated protein } \\ \text { LRP1 } & \text { low density lipoprotein related protein 1 } \\ \text { LPA } & \text { lysophosphatidic acid } \\ \text { MIP2 } & \text { macrophage inflammatory protein } 2 \\ \text { MMPs } & \text { matrix metalloproteases } \\ \text { NO } & \text { nitric oxide } \\ \text { PVA } & \text { polyvinyl alcohol } \\ \text { SPARC } & \text { secreted protein acidic and rich in cysteine } \\ \text { SMCs } & \text { smooth muscle cells } \\ \text { sGC } & \text { soluble guanylyl cyclases } \\ \text { SC } & \text { subcutaneous } \\ \text { TSP } & \text { thrombospondin } \\ \text { TSR } & \text { thrombospondin type I repeat } \\ \text { tTG } & \text { tissue transglutaminase } 2 \\ \text { TGF- } \beta_{1} & \text { transforming growth factor } \beta_{1} \\ \text { TNF- } \alpha & \text { tumor necrosis factor } \alpha \\ \text { UVB } & \text { ultraviolet-B } \\ \text { VLDLR } & \text { very low density lipoprotein receptor } \\ \text { VEGF } & \text { vascular endothelial growth factor } \\ \text { WT } & \text { wild type } \\ & \end{array}$

\section{Introduction}

Thrombospondin (TSP) 1 and TSP2 are matricellular proteins, and as such are released and/or secreted following tissue injury and associate with the extracellular matrix 
(ECM) to exert cellular effects (Reviewed in this issue). In addition to its association with the ECM, TSP1 is a major component of platelet $\alpha$-granules and can also be found in circulation while TSP2 is typically a product of fibroblasts. Despite their high sequence homology, these molecules have largely non-overlapping functions, as exemplified by their unique cellular distribution and temporal expression, as well as by the distinct phenotypes of the respective knockout animals (Crawford et al. 1998; Kyriakides et al. 1998a; Lawler et al. 1998). TSP1 was the first identified endogenous inhibitor of angiogenesis, and its role as a critical regulator of tumor progression via modulation of angiogenesis is well established (Reviewed in (Kazerounian et al. 2008; Zhang and Lawler 2007)). Moreover, a fragment of TSP1 (ABT-510) is in phase II clinical trials as an anti-angiogenic cancer therapy (Baker et al. 2008). Similarly, TSP2 exerts anti-angiogenic effects and can influence processes including inflammation and tissue remodeling (Kyriakides and Bornstein 2003). Although TSP1 and TSP2 are dispensable for developmental angiogenesis, they are critical for proper tissue repair, as will be discussed in this review.

Damage to tissue is resolved through a series of overlapping processes that lead to variable outcomes including resolution, fibrosis, or scarring. Although the resolution of tissue repair is a diverse process that depends on the extent and site of damage, TSP1 and TSP2 are implicated in a number of tissue-injury settings. Overall, TSP1 and TSP2 are critical for proper neovascularization and are typically associated with proper ECM organization, but the molecular mechanisms regulating these processes have not been elucidated. TSP1 and TSP2 are proposed to act through direct interactions with cell receptors and/or indirectly by modulating the composition of the extracellular milieu. Binding of TSP1 and TSP2 to cell-surface receptors involves integrins, integrin associated protein (IAP)/CD47, CD36, heparin sulfate proteoglycans, low density lipoprotein related protein 1 (LRP1), and very low density lipoprotein receptor (VLDLR). These direct interactions lead to alterations in cell proliferation and survival, extracellular matrix remodeling, and blockade of nitric oxide (NO) signaling. Indirect interactions mediated by TSPs include the alteration of levels or bioavailability of effector molecules including basic fibroblast growth factor (bFGF) and vascular endothelial growth factor (VEGF) (Greenaway et al. 2007; Gupta et al. 1999; Taraboletti et al. 1997) as well as matrix metalloproteinase (MMP)-2 and MMP-9, which can alter ECM structure and cell function. In addition, TSP1 can activate transforming growth factor (TGF)- $\beta_{1}$. Historically, the efforts to elucidate these mechanisms have focused on TSP1, and it was assumed that TSP2 shared these functions due to its high sequence and structural homology with TSP1. However, it is now appreciated that TSP1 and TSP2 differ in their mechanisms of action (Fig. 1). For example, TSP2 does not activate TGF- $\beta_{1}$. In addition, TSP1 binds CD47 with higher affinity than TSP2 and is thought to be more efficient in inhibiting NO signaling (Isenberg et al. 2009). Moreover, unlike TSP2, TSP1 cannot inhibit angiogenesis in a threedimensional assay (Krady et al. 2008). However, there are some similarities between the proposed mechanisms of action of TSP1 and TSP2. Specifically, in vitro studies have shown that both TSP1 and TSP2 are capable of binding MMP-2 or MMP-9 and enhancing their cellular uptake and

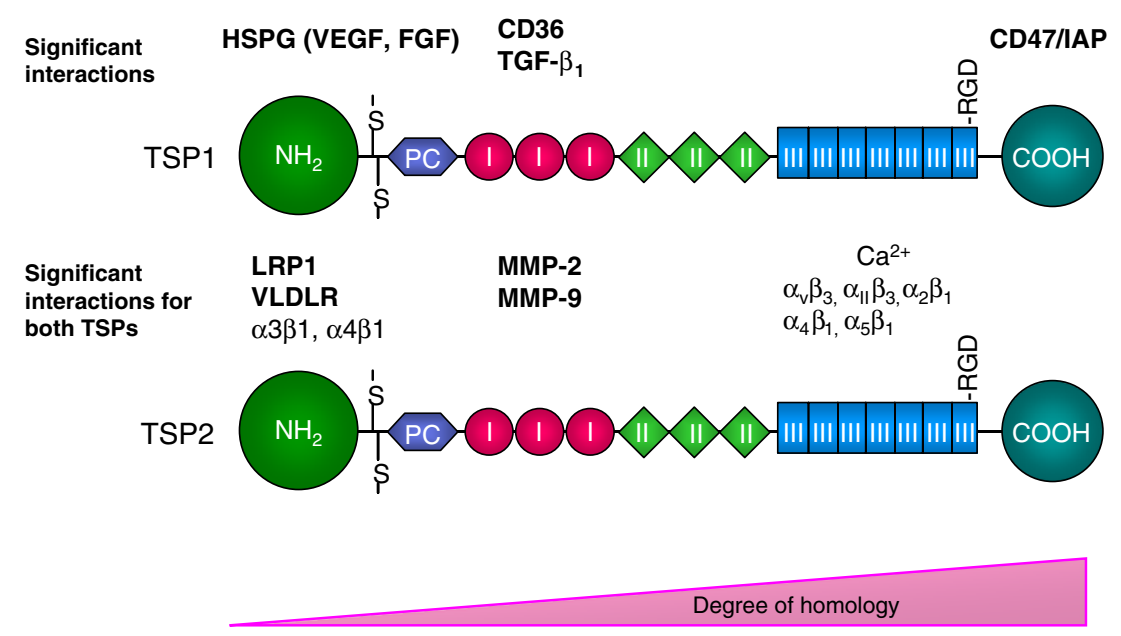

Fig. 1 Schematic diagram of significant TSP1 and TSP2 interactions in tissue repair. Interactions are shown based on their importance for each molecule independently or those verified to be shared by both TSP1 and TSP2. Molecules listed in bold are discussed in the review. All molecules are spatially oriented near the known and putative TSP domains they interact with. $\mathrm{NH}_{2}$, amino terminus includes heparin binding site; PC, pro-collagen homology region; I, type I properdinlike repeats (TSR); II, type II EGF homology repeats; III, type III repeats include calcium binding sites; $\mathrm{COOH}$, carboxy terminus 
degradation (Emonard et al. 2004; Hahn-Dantona et al. 2001; Yang et al. 2000).

In this review we discuss the current understanding of the roles of TSP1 and TSP2 in tissue repair (summarized in Table 1). We focus primarily on their influences in wound healing, ischemia, and the foreign body response but also review several other models of repair-associated processes. For each model, we also discuss the pertinent mechanistic data regarding their function.

\section{Wound healing}

Expression of TSPs during dermal wound repair

Healing of cutaneous wounds requires sequential and overlapping phases of inflammation, cell proliferation/ migration, and tissue remodeling (Singer and Clark 1999). Many bioactive molecules such as cytokines, growth factors, and matricellular proteins including TSP1, TSP2, osteopontin, and secreted protein acidic and rich in cysteine (SPARC) play critical roles in this process. In dermal wound healing, the spatial and temporal expression of TSP1 and TSP2 are distinct (Agah et al. 2002; Kyriakides et al. 1999b). TSP1 expression is typically low in uninjured skin, is induced acutely following wounding (d 1-3), and returns to basal levels as inflammation resolves. TSP1 is found primarily associated with the ECM and in thrombi. Degranulation of the $\alpha$-granules of platelets is the major contributor of TSP1 post injury, but in situ hybridization and immunohistochemistry have also revealed wound bed smooth muscle cells, macrophages and endothelial cells as sources of TSP1 (DiPietro et al. 1996; Raugi et al. 1987). Specifically, in human excisional wounds TSP1 was distributed at the lateral and deep wound margins between 2 and 7 d post wounding, and diminished by d 14 (Raugi et al. 1987). In the same study, vessels adjacent to granulation tissue in d 7 and d 14 wounds displayed greater TSP1 immunoreactivity relative to that in distal vessels. In a mouse study, mRNA for TSP1 was undetectable in normal skin and increased at d 1 following full-thickness wound and was undetectable again at d 10 (DiPietro et al. 1996). This study concluded that macrophage-like cells represented the primary source of TSP1 in wounds.

Table 1 Summary of TSP-associated tissue repair phenotypes

\begin{tabular}{|c|c|c|c|}
\hline Model & TSP1 KO & TSP2 KO & TSP1/TSP2 Double KO \\
\hline \multirow[t]{6}{*}{ Wound healing } & Prolonged inflammation & Enhanced angiogenesis & Prolonged inflammation \\
\hline & $\begin{array}{l}\text { Delayed wound closure, delayed } \\
\text { scab loss and reepithelialization }\end{array}$ & Accelerated wound closure & $\begin{array}{l}\text { Delayed wound closure, delayed scab } \\
\text { loss and reepithelialization }\end{array}$ \\
\hline & Normal angiogenesis & Irregular ECM assembly & Normal angiogenesis \\
\hline & $\begin{array}{l}\text { Altered granulation tissue } \\
\text { morphology }\end{array}$ & Increased MMP-2 and MMP-9 & Altered granulation tissue morphology \\
\hline & Decreased MCP-1 & Increased soluble VEGF & Decreased MCP-1 \\
\hline & Decreased TGF- $\beta$ (total and active) & & Decreased TGF- $\beta$ (total and active) \\
\hline \multirow[t]{4}{*}{ Hindlimb ischemia } & Enhanced angiogenesis & Enhanced angiogenesis & Enhanced angiogenesis \\
\hline & Enhanced blood flow recovery & Enhanced blood flow recovery & Increased platelet-derived SDF-1 \\
\hline & Involves NO signaling & Increased baseline arteriogenesis & \\
\hline & Macrophage-dependent & Increased MMP-9 & \\
\hline Skin Flap & $\begin{array}{l}\text { Increased survival } \\
\text { Involves CD47 and NO signaling }\end{array}$ & Normal & Normal \\
\hline \multirow[t]{6}{*}{$\begin{array}{l}\text { Polyninyl alcohol } \\
\text { sponge Implantation }\end{array}$} & \multirow[t]{6}{*}{ Not determined } & $\begin{array}{l}\text { Enhanced angiogenesis } \\
\text { Increased MMP- } 2, \text { NC TGF- } \beta\end{array}$ & Not determined \\
\hline & & Increased encapsulation & \\
\hline & & Irregular ECM assembly & \\
\hline & & Decreased invasion & \\
\hline & & $\begin{array}{l}\text { Brain: Increased neuroinflammation } \\
\text { and BBB permeability }\end{array}$ & \\
\hline & & Increased MMP-2 and MMP-9 & \\
\hline \multirow[t]{3}{*}{ Foreign body response } & \multirow[t]{3}{*}{ Not determined } & $\begin{array}{l}\text { Enhanced angiogenesis } \\
\text { Increased MMP-2 }\end{array}$ & Not determined \\
\hline & & Increased encapsulation & \\
\hline & & Irregular ECM assembly & \\
\hline
\end{tabular}


TSP2 is present in normal skin at very low levels in an ECM-associated pattern (Agah et al. 2004; Kyriakides et al. 1998b). Deposition of TSP2 is increased in dermal wounds as early as $\mathrm{d} 3$ and reaches peak levels at $\mathrm{d} 10$. Expression of TSP2 in platelets and endothelial cells (ECs) is below detection levels, and the major contributors to wound TSP2 are fibroblasts and smooth muscle cells (Agah et al. 2004). Immunohistochemistry revealed deposition of TSP2 in granulation tissue ECM and in fibroblast-like cells following full thickness wounds (Kyriakides et al. 1999b). The spatiotemporal expression of TSP1 and TSP2 implicates their unique functions in wound healing. This distinction is underscored by the fact that the wound site is dramatically altered between the peaks in expression of the two molecules. TSP1 is induced early in wound healing, concomitant with thrombus formation, edema and inflammation. TSP2 expression occurs after resolution of the inflammatory phase and during granulation tissue remodeling.

\section{Thrombospondin 1 and wound healing}

Wound healing studies in TSP1-null mice indicated delayed repair, characterized by loosely compacted and disorganized granulation tissue (Agah et al. 2002). Macrophage influx and blood vessel density following wounding were reduced compared to WT wounds (Agah et al. 2002). In the same study, TSP1-null wounds were found to contain decreased levels of both total and active TGF- $\beta_{1}$. TSP 1 is believed to be a major in vivo activator of TGF- $\beta_{1}$ as TSP1-null mice revealed suppressed active TGF- $\beta_{1}$ levels, which were restored to normal levels by the addition of the TSP1-specific peptide activating sequence (KRFK) (Crawford et al. 1998). The importance of TSP1-mediated TGF- $\beta_{1}$ activation is supported by the observation that collagen gel contraction, an in vitro model for wound contraction, was enhanced by addition of TSP1, with a concordant increase in active TGF- $\beta_{1}$, and reduced by antibody-mediated functional knockdown of either TSP1 or TGF- $\beta_{1}$ (Sakai et al. 2003).

Wound healing in TSP1/TSP2 double-null mice phenocopies that in TSP1-null animals, indicating that the initial loss of TSP1 dictates the course for wound healing (Agah et al. 2002). Similarly, transient knockdown of TSP1 using an antisense oligomer strategy led to a decreased rate of reepithelization and delayed dermal reorganization, (DiPietro et al. 1996). It is important to note that this oligomer strategy decreased wound macrophage TSP1 production (55-66\% reduction) but did not affect previously synthesized TSP1 (platelets, epidermal-dermal junction) (DiPietro et al. 1996).

Interestingly, excisional wounds in transgenic mice with TSP1 expression controlled by a keratin promoter displayed delayed healing with decreased granulation tissue formation and wound neovascularization (Streit et al. 2000). Uninjured skin in transgenic mice had no obvious structural changes and had normal basal vessel density, architecture, and permeability (Streit et al. 2000). Delayed healing was attributed to an increase in apoptosis in the wound bed, involving mostly fibroblasts. In the same study it was shown that addition of TSP1 decreased the migration of fibroblast and ECs in vitro. Moreover, there was reduced EC proliferation in the presence of TSP1 in vitro. It should be noted that the quantity and duration of TSP1 expression in these mice exceeds that of WT mice, which is limited to the first $5 \mathrm{~d}$ post-injury.

\section{Thrombospondin 2 influences wound healing}

Full thickness wounds in TSP2-null animals healed at an accelerated rate compared to WT and displayed alterations in the remodeling phase of healing (Kyriakides et al. 1999b). Complete reepithelization of full thickness excisional wounds occurred earlier than WT, and the epithelial layer displayed increased thickness. Granulation tissue at the wound site was disorganized with a basket weave morphology of collagen fibers and altered distribution of fibronectin. In addition, TSP2-null wounds were found to have increased cellular content and vascular density, which is consistent with the anti-angiogenic function of TSP2. Subsequent studies of TSP2-null wounds revealed increased MMP-2 and MMP-9 in the ECM, as well as increased soluble vascular endothelial growth factor (VEGF) in wound tissue (Krady et al. 2008; MacLauchlan et al. 2009). In vitro studies have shown that TSP1 can directly bind and sequester VEGF, serving to decrease VEGF receptormediated signaling (Greenaway et al. 2007). Despite the in vitro observation that TSP1 and TSP2 can induce apoptosis and prevent proliferation, neither process was influenced by the lack of TSP2 during wound healing. Specifically, detection of proliferating and apoptotic cells in wounds revealed similar levels between TSP2-null and WT mice. Although myofibroblast content was equivalent between TSP2-null and WT wound beds, TSP2-null wound fibroblasts displayed altered morphology in stressed collagen gels and reduced contraction of relaxed collagen gels, indicating an inherent deficit in contractility (MacLauchlan et al. 2009). Taken together, these findings suggest that TSP2 influences fibroblast-ECM interactions, possibly through MMPmediated ECM remodeling.

The observation that TSP2 expression increases with age and contributes to the delayed healing of aged mice provides further support for its critical role in wound healing (Agah et al. 2004). Interestingly, the same study demonstrated that peak TSP2 expression shifted to d 14 in aged mice, as was the increase in MMP-2 in aged TSP2-null wounds. 


\section{TSPs in ischemia-induced angiogenesis and arteriogenesis}

Hypoxia can trigger inflammation-driven angiogenesis in order to improve blood-flow to ischemic tissues. The function of TSPs has been investigated in two ischemic models, namely hindlimb ischemia and random myocutaneous flap. Similar to wound healing, hindlimb ischemia in mice, accomplished by ligation or excision of the femoral artery, has been used as a robust model of physiologic angiogenesis and arteriogenesis (Heil et al. 2006). Following excision, there is a resulting drop in pressure in the distal vasculature and a pressure gradient causes increased flow through preexisting collaterals (Heil and Schaper 2004). A number of responses are then elicited, including activation of the endothelium, up-regulation of adhesion molecules, and inflammatory factors. These responses are accompanied by invasion of circulating monocytes that contribute to the digestion of the ECM. Smooth muscle cells, in turn, migrate and proliferate causing enlargement of blood vessels and eventually allow for restoration of fluid shear and wall stresses to normal levels. A number of conditions determine the overall efficacy of the growth of collateral vessels. These include the existence of an arterial network that connects the microcirculation, the activation of the endothelium by elevated fluid shear stress, the invasion of bone marrowderived cells, and the proliferation of ECs and smooth muscle cells (SMCs). In addition, this model causes regional hypoxia and mismatch between oxygen supply and demand in skeletal myocytes in the distal limb (Heil and Schaper 2004; Heil and Schaper 2005). Once a stable, collateral circulation is established, the improvement in distal blood flow and shear stress triggers an increase in capillary angiogenesis, thus increasing capillary to fiber ratios and oxygen delivery to the dependent portions of the lower limb. Therefore, proportionally regulated arteriogenesis and angiogenesis are necessary to improve nutritive blood flow to tissue and promote functional limb salvage.

TSP2 expression in ischemic muscle was robust in ischemic muscles at $1 \mathrm{wk}$ post-injury, followed by a drop in expression between 1 and $3 \mathrm{wks}$, and a subsequent increase at 4 wks (Krady et al. 2008). Immunohistochemical analysis indicated an extensive association of TSP2 with muscle fibers and interstitial fibroblasts early in the recovery process. At 4 wks, TSP2 expression was also observed in close association with blood vessels. TSP2-null mice were shown to have enhanced arteriogenesis, angiogenesis and recovery of blood flow following ischemia in comparison to control mice. Specifically, TSP2-null mice were shown to have an increased number of vessels and capillary-to-fiber ratios throughout the recovery period. Remarkably, compared with WT mice, baseline arteriogenesis was greater in TSP2-null mice as shown by quantitative angiography.
Moreover, the number of collaterals was found to be higher in TSP2-null mice, indicating the presence of an enhanced arterial network. Increased baseline arteriogenesis in TSP2null limbs suggested that the ability to use existing collaterals to supply blood flow to the distal limb is enhanced in these mice. Contraction-stimulated hyperemia in the gastrocnemius muscle in WT and TSP2-null mice at baseline, induced by electrical stimulation of the adductor muscle groups, was greater in TSP2-null mice. Taken together, these findings suggest that TSP2 functions as a critical regulator of the vasodilation necessary for the gradual return of blood flow to normal levels. These observations are the first to link any TSP with the process of arteriogenesis. In a separate study using the same model, it was shown that TSP2-null mice display normal recovery of blood flow in the first $72 \mathrm{hrs}$ following ischemia (Isenberg et al. 2009). This is not surprising, since TSP2 is not expressed during this time frame.

The spatiotemporal expression of TSP1 mRNA in the hindlimb ischemia model has recently been described (Brechot et al. 2008). Similar to wound healing, in situ hybridization revealed high levels of TSP1 expression in macrophages at d 4 and d 6 post-injury. At d 16 and d 21 TSP1 expression was diminished and was predominantly associated with EC. In the same study, TSP1-null mice were protected from ischemia-induced necrosis due to increases in angiogenesis and muscle fiber regeneration. However, in this study, C57B16 WT mice displayed excessive necrosis following excision of the femoral artery, which is highly unusual for this strain. Interestingly, the protective effect of TSP1 deficiency was reversed following macrophage depletion in TSP1-null mice. Moreover, TSP1null macrophages isolated from $\mathrm{d} 4$ ischemic muscles were found to be less pro-inflammatory. Thus, in this model it appears that macrophage-derived TSP1 plays a critical role in inflammation-induced angiogenesis.

Analysis of the ischemic response in double TSP1/TSP2null mice showed an improved phenotype consistent with that observed in the single TSP1-null and TSP2-null mice and was attributed to increased angiogenesis due to increased MMPs and platelet production (Kopp et al. 2006). In the same study, bone marrow transplantation experiments showed that the improved phenotype could be transferred to wild type mice that received double-null marrow. This observation prompted the investigators to hypothesize that TSPs derived from circulating cells could regulate the ischemic response. Specifically, it was proposed that platelet-derived TSPs regulate ischemia-induced angiogenesis. It should be noted that platelets do not contain TSP2 and TSP2-null platelets have an inherent aggregation defect (Kyriakides et al. 2003). Moreover, a recent report showed that in the presence of exogenous NO TSP1-null platelets fail to aggregate in response to thrombin (Isenberg et al. 2007c). Thus, reintroduction of 
double-null platelets in WT mice might have produced results that are more relevant in the context of suboptimal platelet activation.

\section{The Foreign Body Response (FBR)}

In many ways the FBR is similar to wound healing in that both initiate with tissue injury and trigger inflammatory responses. However, whereas inflammation gives way to healing in normal repair, implantation of a biomaterial or other persistent foreign body presents prolonged inflammatory signals that elicit fibrosis, formation of foreign body giant cells (FBGCs) and almost complete regression of vascular structures, leading to the formation of mostly avascular collagenous capsules (Anderson et al. 2008). Experimentally, solid biomaterials implanted SC undergo encapsulation in the time span of 4 wks. Alternatively, implantation of porous sponges (polyvinyl alcohol, PVA) induces sponge granuloma formation within 3 wks, which allows evaluation of angiogenesis and ECM remodeling (Reviewed in (Kyriakides and Bornstein 2003)). Thus far, only the role of TSP2 in the FBR has been studied. TSP1 might also influence the FBR, particularly due to its antiangiogenic function and its role in wound inflammation.

In the context of the FBR, TSP2 expression was high within the foreign body capsule, at the implant interface, and was associated with fibroblasts proximal to the capsule (Kyriakides et al. 1999a; Kyriakides et al. 2001b). Silicone (PDMS) disks implanted subcutaneously (SC) into TSP2null animals induced the formation of capsules that were thicker than WT, irregular in organization, and contained an increased number of blood vessels (Kyriakides et al. 1999a). The collagenous capsule surrounding the implant lacked organization and was associated with decreased collagen packing and a loss of the parallel arrangement of collagen fibers (Kyriakides et al. 1999a). This was the first demonstration of the FBR with sustained capsule vascularization. Similar to solid implants, PVA sponges implanted in TSP2-null animals induced increased angiogenesis and less organized fibrosis than WT (Kyriakides et al. 2001b). Moreover, solid implants and PVA sponges treated with a gene-activated matrix containing TSP2 antisense plasmid and implanted in WT mice induced thicker, irregular, and well-vascularized capsules that displayed altered fibronectin distribution and misaligned collagen fibers (Kyriakides et al. 2001a). These changes were associated with increased MMP-2; no significant change in active TGF- $\beta_{1}$ was detected (Kyriakides et al. 2001b). In the same study restoration of TSP2 by cDNA delivery reversed the TSP2-null phenotype. Consistent with the role of matricellular proteins in tissue repair, SPARCTSP2 double-null mice were shown to have increased fibrovascular invasion into PVA sponges, associated with increased levels of MMP-2 (Puolakkainen et al. 2005).

A recent study involving implantation of PVA sponges in the mouse brain cortex confirmed the significance of TSP2 in regulating fibrotic and angiogenic responses, but underscores the tissue specificity of the FBR as neuroinflammation and permeability of the blood brain barrier were severely compromised in TSP2-null animals (Tian and Kyriakides 2009). Previous studies using TSP2-null animals did not demonstrate altered macrophage or inflammatory cell recruitment to the biomaterial in the FBR. As in the SC space, PVA sponges in the TSP2-null brain displayed increased levels of MMP-2 and MMP-9.

\section{Thrombospondins in models of skin inflammation and UV light damage}

Adult skin microvasculature is mostly quiescent, except when angiogenesis is stimulated by damage, pathologic conditions, and during growth of the hair follicle (Detmar 2000). The role of TSPs in normal skin angiogenesis is well appreciated (Detmar 2000) and is discussed here briefly, focusing on damage models including photodamage and inflammation.

Hair growth requires coordinated induction and regression of vessels proximal to the follicle during the anagen and catagen phases of the hair life cycle, respectively (Yano et al. 2003). TSP1 expression was induced during the involution phase, which is characterized by vascular regression and follicle growth. Involution in TSP1-null mice was significantly prolonged and characterized by increased vascularity, resulting in a longer hair growth phase and longer follicles (Yano et al. 2003). Moreover, transgenic overexpression of TSP1 resulted in the opposite phenotype, with decreased vascularization of the follicle resulting in shorter hair follicles (Yano et al. 2003). These changes are consistent with the requirement for vascularization of the follicle for proper growth and the well documented anti-angiogenic function of TSP1 (Detmar 2000).

Ultraviolet-B (UVB) irradiation induces dermal damage that is associated with changes in epithelial cells, leading to ECM degradation, wrinkle formation, and vascular changes, including dilation and hyperpermeability (Yano et al. 2002). Transgenic TSP1 mice were protected against UVB damage, and this protection was attributed to blocked induction of vascular responses, as measured by decreased vascularization, decreased EC proliferation, and induction of EC apoptosis (Yano et al. 2002). Furthermore, these mice were protected against wrinkle formation (Yano et al. 2002). In WT mice, TSP1 was depressed while VEGF and transient neovascularization were induced by a single dose of UVB irradiation (Yano et al. 2004). This hypothesis is supported by UVB-mediated induction of angiogenesis and con- 
comitant down-regulation of TSP1 in human subjects (Yano et al. 2005). The role of TSP2 has not been explored in these models.

There is a clear role for angiogenesis in the development of inflammatory diseases, including chronic skin inflammation (Jackson et al. 1997). TSP1 and TSP2, as well as the receptor CD36, are induced by inflammatory stimuli (Lange-Asschenfeldt et al. 2002; Velasco et al. 2009). TSP1 was present in the basement membrane of the dermalepidermal junction in non-inflamed skin and was detected in blood vessels and more strongly in the epidermis following induction of inflammation (Velasco et al. 2009). Inflammation-induced TSP2 was associated primarily with dermal fibroblasts (Lange-Asschenfeldt et al. 2002). Lack of either TSP1 or TSP2 resulted in increased inflammationinduced vessel density, edema, and inflammatory infiltration leading to prolonged and exacerbated reactions (Lange-Asschenfeldt et al. 2002; Velasco et al. 2009). Interestingly, TSP2-null mice displayed increased rolling of leukocytes in non-inflamed skin, which might enhance leukocyte trafficking and influx into tissues (LangeAsschenfeldt et al. 2002). Moreover, inflammatory stimuli induced interleukin (IL) $-1 \beta$, macrophage inflammatory protein 2 (MIP2), and tumor necrosis factor (TNF) $-\alpha$ to a greater extent in TSP1-null animals, contributing to the proinflammatory state (Velasco et al. 2009). Although this study did not explore the role of MMPs in the context of this model, it is interesting to note that IL- $1 \beta$ is activated by MMP-mediated cleavage (Schonbeck et al. 1998) and MMPs would be expected to be high in the TSP1-null environment. Consistent with the observations outlined above, over-expression of TSP1 in transgenic mice was associated with protection against edema formation due to decreased vessel density and permeability (Velasco et al. 2009).

\section{Thrombospondin in other healing models}

The roles of TSPs in other healing models are quickly becoming appreciated. In the context of the anti-Thy1induced kidney injury, TSP1 was associated with progression to kidney fibrosis by activation of TGF- $\beta_{1}$ (Reviewed in (Basile 1999; Hugo 2003)). In various eye injury models TSPs have been implicated in a variety of roles (Reviewed in (Hiscott et al. 2006)). The eye represents a unique site for wound healing because it has avascular and immunoprivileged regions. TSP1 is induced during corneal ischemia (Suzuma et al. 1999) and TSP1-null mice were protected against vessel obliteration following oxygen-induced retinopathy, due to increased EC density and decreased EC apoptosis (Wang et al. 2003). Alternatively, exogenous TSP1 and antibody-mediated knockdown of TSP1 demon- strated a positive role for TSP1 on re-epithelization of corneal scratch wounds (Uno et al. 2004). The role of TSP2 in these models is not well studied, but is strongly induced concomitant with VEGF during healing of corneal alkali burns (Yan et al. 2007). Moreover, in a model of oxygen induced retinal ischemia in CYP1B1-null mice TSP2 expression was induced by reactive oxygen species (ROS) and the increase was sensitive to antioxidants (Tang et al. 2009). Consistent with a role of ROS in inducing TSP2 expression, constitutive active Rac $\mathrm{V}^{12}$ driven ROS production induced TSP2 in human aortic endothelial cells (Lopes et al. 2003).

As discussed above, there is a critical role of TSPs in ischemia-induced angiogenesis. Consistent with this suggestion, it was shown that cerebral ischemia generated by stroke induced TSP1 expression acutely (1 to $72 \mathrm{hrs}$ post insult) and TSP2 expression 2 wks following injury (Lin et al. 2003). In this model, the pattern of TSP1 and TSP2 expression correlated temporally with just prior to and just after the angiogenic component of ischemia, respectively (Lin et al. 2003). However, it is unclear whether TSP1 or TSP2 are required for proper healing following stroke. Each of these healing models represents exciting avenues for future research.

\section{Mechanism of action of TSPs}

As discussed above, multiple mechanisms have been proposed to explain the roles of TSP1 and TSP2 in tissue repair, and especially during angiogenesis (Table 1). Generally, TSPs are believed to induce EC apoptosis and prevent EC proliferation, affect cell migration, and block NO signaling. In this section we evaluate the in vitro data supporting each of these mechanisms and their relevance in vivo.

TSP1, TSP2, and MMPs

MMPs play critical roles in wound healing, in particular due to their established pro-angiogenic function (PageMcCaw et al. 2007; Yang et al. 2000). The gelatinases MMP-2 and MMP-9 complex with either TSP1 or TSP2 through their TSP type I (TSR) repeats (Bein and Simons 2000). This complex is recycled by its interaction with the scavenger receptor, LRP1 (Emonard et al. 2004; HahnDantona et al. 2001; Yang et al. 2001). TSP1 and TSP2 are not cleaved by either MMP-2 or MMP-9 in this complex (Bein and Simons 2000; Yang et al. 2000). An inverse correlation between the levels of TSP2 and MMPs was observed in vivo in dermal wound healing, hindlimb ischemia, and the FBR (Krady et al. 2008; Kyriakides et al. 2001b; MacLauchlan et al. 2009; Tian and Kyriakides 2009). More importantly, in situ zymographic analysis revealed increased gelatinase activity in TSP2- null cells 
and tissues (Krady et al. 2008). Depending on the injury model, MMP-2, MMP-9, or both were influenced by the deficiency of TSP2. Presumably, this is a reflection of the cellular variability and resulting spatiotemporal expression of these enzymes in the different models. For example, both MMP-2 and MMP-9 were increased in TSP2-null dermal wounds (MacLauchlan et al. 2009) whereas in hindlimb ischemia only the latter was increased (Krady et al. 2008).

MMPs have multiple roles in tissue repair including their ability to remodel granulation tissue and modulate the bioactivity and levels of molecules such as growth factors and cytokines. For example, the high levels of MMPs in TSP2-null dermal wounds were associated with increased amounts of soluble VEGF. This observation was consistent with previous studies demonstrating that MMPs are capable of releasing matrix-bound VEGF (Belotti et al. 2003; Bergers et al. 2000; Lee et al. 2005). Interestingly, in TSP2-null dermal wounds the increase in MMPs was also shown to influence the levels of tissue transglutaminase 2 (tTG) (Agah et al. 2005). tTG plays critical roles in the stabilization of ECM by the introduction of $\gamma$-glutamyl- $\varepsilon$ amino lysyl isopeptide cross-links into collagen, fibronectin, and other matrix proteins (Lorand and Graham 2003). Thus, by modulating the levels of MMP-2 and/or MMP-9 TSP2 can indirectly influence the stability and integrity of the ECM as well as the levels of at least one growth factor. Moreover, a recent study has implicated MMP9 in collagen fibrillogenesis during dermal wound healing (Kyriakides et al. 2009). Thus, the increased levels of MMPs in TSP2-null wounds could also influence ECM assembly.

TSPs and TGF- $\beta_{1}$ activation

TSP1 can activate TGF- $\beta_{1}$, but activation requires both a TGF- $\beta_{1}$ binding site (GGWSHW) and an activation site (KRFK); TSP2 lacks the activation site (Schultz-Cherry et al. 1995) and TSP2 deficiency has not been associated with changes in TGF- $\beta_{1}$ activation (Kyriakides et al. 2001a). Active TGF- $\beta_{1}$ levels were decreased in the TSP1-null animals (Crawford et al. 1998), as expected based on the ability of TSP1 to activate latent TGF- $\beta_{1}$ (Schultz-Cherry et al. 1995; Yee et al. 2004). The biochemical activation pathway of TGF- $\beta_{1}$ is well described and can be achieved by both proteolytic and non-proteolytic mechanisms (Jenkins 2008) (Annes et al. 2003). Active TGF- $\beta_{1}$ is secreted in the latent form as a dimer with its proprotein pro-TGF- $\beta_{1}$ (referred to as the latency associated protein (LAP)) (Jenkins 2008). The interaction of TSP1 with TGF- $\beta_{1}$ releases the active TGF- $\beta_{1}$ molecule from LAP (Annes et al. 2003). The interactions between TSP1 and TGF- $\beta_{1}$ are well described (Reviewed in (Murphy-Ullrich and Poczatek 2000)) and include regions of the TSR repeats (Schultz-Cherry et al. 1994), which interact with the active TGF- $\beta_{1}$ (WSXW,
(Young and Murphy-Ullrich 2004)) and LAP (KRFK and LSKL sequences (Crawford et al. 1998; Ribeiro et al. 1999; Schultz-Cherry et al. 1995)) to disrupt the complex.

TSPs and CD36 interactions

A mechanism for the anti-angiogenic effect of TSP1 was shown to involve the interaction of the type I repeats of TSP1 with the scavenger receptor CD36 on ECs (Dawson et al. 1997). Subsequently, a study determined the downstream events that included activation of p59fyn, leading to activation of p38MAPK, caspase 3-like proteases, and induction of EC apoptosis (Jimenez et al. 2000). In the same study, in vivo evidence for the involvement of this mechanism in limiting angiogenesis was provided in a tumor model. However, the importance of these mechanisms in the regulation of physiological angiogenesis in wound healing or ischemia has not been established. In fact, in ischemia models it appears that the primary receptor for TSP1 in vascular cells is CD47 and not CD36 (Isenberg et al. 2008b). It is also unclear whether TSP2 can induce the activation of this cascade, even though binding of TSP2 to CD36 on EC has been reported (Simantov et al. 2005). In addition, a recent report has shown that HUVEC, which express low levels of CD36, remained insensitive to exogenous TSP2 even when transfected with a CD36 cDNA (Oganesian et al. 2008). Thus, the significance of TSP2-CD36 interaction in injury-induced angiogenesis is unclear.

\section{TSPs and blockade of NO signaling}

A major canonical pro-angiogenic target of nitric oxide (NO) is the activation of soluble guanylyl cyclases (sGC), leading to increased intracellular pools of the second messenger cGMP (Hoefer et al. 2006). Recently, TSP1 was demonstrated to block nitric oxide (NO) mediated accumulation of cGMP, revealing a new mechanism to blockade angiogenesis (Reviewed in (Isenberg et al. 2008a)). At low, physiologic levels of TSP1, this interaction was mediated by the cell surface receptors CD47/integrin associated protein (IAP) through undefined downstream mediators (Isenberg et al. 2006a). At nanomolar concentrations, TSP1 was shown to interact with the scavenger receptor $\mathrm{CD} 36$ and synergize with CD47 to achieve this effect (Isenberg et al. 2006b; Isenberg et al. 2005). Because exogenous myristic acid can activate eNOS through CD36 (Zhu and Smart 2005) and TSP1 peptides corresponding to the CD36 binding site inhibit CD36 mediated myristic acid uptake (Isenberg et al. 2008a), it has been implied that TSP1 might inhibit eNOS activity. Specifically, decreased intracellular myristic acid might depress eNOS palmitoylation to achieve altered activity (Isenberg et al. 2007a). However, there is no direct evidence demonstrating that TSP1 decreases eNOS activity 
and the importance of this proposed activity has not been verified in vivo. The role of TSP2 in blocking NO signaling is less well studied. However, TSP2 was recently described to have lower affinity for CD47, and to be less active in blocking NO-mediated cell adhesion (Isenberg et al. 2009). This study also implied that TSP2 could decrease cGMP accumulation in TSP1-null ECs by using a morpholino knockdown strategy (Isenberg et al. 2009), but failed to demonstrate a reduction in TSP2 protein levels. A second possible TSP-mediated anti-angiogenic mechanism involves the well-documented ability of TSP1 to inhibit NO signaling in EC and SMC (Reviewed in (Isenberg et al. 2008a)). According to several studies, TSP1 is an antagonist of NO/ cGMP signaling in ECs and has a biphasic effect on NO production that is dependent on concentration (Isenberg et al. 2005). Specifically, at physiological concentrations TSP1 acts via its receptor CD47 to limit sGC activation. In addition, at supraphysiological concentrations, TSP1 can be inhibitory via CD36, but CD47 is necessary for this effect. Via these interactions, TSP1 acts as a potent inhibitor of NO-stimulated EC proliferation, adhesion, and migration. A series of in vivo studies utilizing genetic and biochemical approaches have established the importance of the TSP1CD47 interaction in regulating NO signaling in vivo in the context of ischemic injury. Specifically, TSP1-null mice displayed enhanced tissue survival in a random myocutaneous flap model for ischemic injury due to increased NO-mediated vasodilation (Isenberg et al. 2007b).

\section{Conclusion}

Since the discovery of TSP1 and TSP2, many studies have focused on elucidating their functional significance and mechanism of action. Generation of TSP1-null and TSP2null mice revealed that both proteins are dispensable in embryonic development and do not play critical roles in homeostatic processes. However, both TSP-null mouse strains display abnormal responses to injury and the resultant phenotypes have provided clues to their mechanisms of action. Based on such studies, we suggest that TSP1 has a critical role in the inflammatory phase of tissue repair and antagonizes NO signaling in ischemia. Moreover, loss of TSP1 is associated with reduced activation of TGF- $\beta_{1}$ in dermal wound healing. TSP 2 on the other hand, is primarily involved in tissue remodeling via the modulation of the levels of MMP-2 and MMP-9. Despite the documented direct negative effects of TSP1 and TSP2 on EC survival and/or growth in vitro, it not clear whether such mechanisms are involved in tissue repair. More detailed analysis of proliferation and apoptosis during tissue repair is needed to clarify this issue. In addition, studies utilizing tissue-specific deletions of TSP1 and/or
TSP2, as well as the generation of knock-in mice with mutant forms of these proteins, should provide additional clues to their precise mechanisms of action.

Acknowledgements We thank Dr. Paul Bornstein for critical reading of the manuscript.

Open Access This article is distributed under the terms of the Creative Commons Attribution Noncommercial License which permits any noncommercial use, distribution, and reproduction in any medium, provided the original author(s) and source are credited.

\section{References}

Agah A, Kyriakides TR, Lawler J, Bornstein P (2002) The lack of thrombospondin-1 (TSP1) dictates the course of wound healing in double-TSP1/TSP2-null mice. Am J Pathol 161:831-839

Agah A, Kyriakides TR, Letrondo N, Bjorkblom B, Bornstein P (2004) Thrombospondin 2 levels are increased in aged mice: consequences for cutaneous wound healing and angiogenesis. Matrix Biol 22:539-547

Agah A, Kyriakides TR, Bornstein P (2005) Proteolysis of cell-surface tissue transglutaminase by matrix metalloproteinase- 2 contributes to the adhesive defect and matrix abnormalities in thrombospondin2-null fibroblasts and mice. Am J Pathol 167:81-88

Anderson JM, Rodriguez A, Chang DT (2008) Foreign body reaction to biomaterials. Semin Immunol 20:86-100

Annes JP, Munger JS, Rifkin DB (2003) Making sense of latent TGFbeta activation. J Cell Sci 116:217-224

Baker LH, Rowinsky EK, Mendelson D, Humerickhouse RA, Knight RA, Qian J, Carr RA, Gordon GB, Demetri GD (2008) Randomized, phase II study of the thrombospondin-1-mimetic angiogenesis inhibitor ABT-510 in patients with advanced soft tissue sarcoma. J Clin Oncol 26:5583-5588

Basile DP (1999) The transforming growth factor beta system in kidney disease and repair: recent progress and future directions. Curr Opin Nephrol Hypertens 8:21-30

Bein K, Simons M (2000) Thrombospondin type 1 repeats interact with matrix metalloproteinase 2. Regulation of metalloproteinase activity. J Biol Chem 275:32167-32173

Belotti D, Paganoni P, Manenti L, Garofalo A, Marchini S, Taraboletti G, Giavazzi R (2003) Matrix metalloproteinases (MMP9 and MMP2) induce the release of vascular endothelial growth factor (VEGF) by ovarian carcinoma cells: implications for ascites formation. Cancer Res 63:5224-5229

Bergers G, Brekken R, McMahon G, Vu TH, Itoh T, Tamaki K, Tanzawa K, Thorpe P, Itohara S, Werb Z, Hanahan D (2000) Matrix metalloproteinase- 9 triggers the angiogenic switch during carcinogenesis. Nat Cell Biol 2:737-744

Brechot N, Gomez E, Bignon M, Khallou-Laschet J, Dussiot M, Cazes A, Alanio-Brechot C, Durand M, Philippe J, Silvestre JS, Van Rooijen N, Corvol P, Nicoletti A, Chazaud B, Germain S (2008) Modulation of macrophage activation state protects tissue from necrosis during critical limb ischemia in thrombospondin-1deficient mice. PLoS ONE 3:e3950

Crawford SE, Stellmach V, Murphy-Ullrich JE, Ribeiro SM, Lawler J, Hynes RO, Boivin GP, Bouck N (1998) Thrombospondin-1 is a major activator of TGF-betal in vivo. Cell 93:1159-1170

Dawson DW, Pearce SF, Zhong R, Silverstein RL, Frazier WA, Bouck NP (1997) CD36 mediates the In vitro inhibitory effects of thrombospondin-1 on endothelial cells. J Cell Biol 138:707-717

Detmar M (2000) The role of VEGF and thrombospondins in skin angiogenesis. J Dermatol Sci 24(Suppl 1):S78-84 
DiPietro L, Nissen N, Gamelli R, Koch A, Pyle J, Polverini P (1996) Thrombospondin 1 synthesis and function in wound repair. Am J Pathol 148:1851-1860

Emonard H, Bellon G, Troeberg L, Berton A, Robinet A, Henriet P, Marbaix E, Kirkegaard K, Patthy L, Eeckhout Y, Nagase H, Hornebeck W, Courtoy PJ (2004) Low density lipoprotein receptorrelated protein mediates endocytic clearance of pro-MMP-2.TIMP2 complex through a thrombospondin-independent mechanism. J Biol Chem 279:54944-54951

Greenaway J, Lawler J, Moorehead R, Bornstein P, Lamarre J, Petrik J (2007) Thrombospondin-1 inhibits VEGF levels in the ovary directly by binding and internalization via the low density lipoprotein receptor-related protein-1 (LRP-1). J Cell Physiol 210: 807-818

Gupta K, Gupta P, Wild R, Ramakrishnan S, Hebbel RP (1999) Binding and displacement of vascular endothelial growth factor (VEGF) by thrombospondin: effect on human microvascular endothelial cell proliferation and angiogenesis. Angiogenesis 3:147-158

Hahn-Dantona E, Ruiz JF, Bornstein P, Strickland DK (2001) The low density lipoprotein receptor-related protein modulates levels of matrix metalloproteinase 9 (MMP-9) by mediating its cellular catabolism. J Biol Chem 276:15498-15503

Heil M, Schaper W (2004) Influence of mechanical, cellular, and molecular factors on collateral artery growth (arteriogenesis). Circ Res 95:449-458

Heil M, Schaper W (2005) Cellular mechanisms of arteriogenesis. Exs: $181-91$

Heil M, Eitenmuller I, Schmitz-Rixen T, Schaper W (2006) Arteriogenesis versus angiogenesis: similarities and differences. J Cell Mol Med 10:45-55

Hiscott P, Paraoan L, Choudhary A, Ordonez JL, Al-Khaier A, Armstrong DJ (2006) Thrombospondin 1, thrombospondin 2 and the eye. Prog Retin Eye Res 25:1-18

Hoefer IE, van Royen N, Jost MM (2006) Experimental models of arteriogenesis: differences and implications. Lab Anim (NY) $35: 36-44$

Hugo C (2003) The thrombospondin 1-TGF-beta axis in fibrotic renal disease. Nephrol Dial Transplant 18:1241-1245

Isenberg JS, Ridnour LA, Perruccio EM, Espey MG, Wink DA, Roberts DD (2005) Thrombospondin-1 inhibits endothelial cell responses to nitric oxide in a cGMP-dependent manner. Proc Natl Acad Sci USA 102:13141-13146

Isenberg BC, Williams C, Tranquillo RT (2006a) Small-diameter artificial arteries engineered in vitro. Circ Res 98:25-35

Isenberg J, Ridnour L, Dimitry J, Frazier W, Wink D, Roberts D (2006b) CD47 is necessary for inhibition of nitric oxidestimulated vascular cell responses by thrombospondin-1. J Biol Chem 281:26069-26080

Isenberg J, Jia Y, Fukuyama J, Switzer C, Wink D, Roberts D (2007a) Thrombospondin-1 inhibits nitric oxide signaling via CD36 by inhibiting myristic acid uptake. J Biol Chem 282:15404-15415

Isenberg JS, Hyodo F, Matsumoto K, Romeo MJ, Abu-Asab M, Tsokos M, Kuppusamy P, Wink DA, Krishna MC, Roberts DD (2007b) Thrombospondin-1 limits ischemic tissue survival by inhibiting nitric oxide-mediated vascular smooth muscle relaxation. Blood 109:1945-1952

Isenberg JS, Romeo MJ, Yu C, Yu CK, Nghiem K, Monsale J, Rick ME, Wink DA, Frazier WA, Roberts DD (2007c), Thrombospondin-1 stimulates platelet aggregation by blocking the anti-thrombotic activity of nitric oxide/cGMP signaling. Blood 613-623

Isenberg JS, Frazier WA, Roberts DD (2008a) Thrombospondin-1: a physiological regulator of nitric oxide signaling. Cell Mol Life Sci 65:728-742

Isenberg JS, Roberts DD, Frazier WA (2008b), CD47. A New Target in Cardiovascular Therapy. Arterioscler Thromb Vasc Biol 615-621
Isenberg J, Annis D, Pendrak M, Ptaszynska M, Frazier W, Mosher D, Roberts D (2009) Differential interactions of thrombospondin-1, -2 , and -4 with CD47 and effects on cGMP signaling and ischemic injury responses. J Biol Chem 284:1116-1125

Jackson J, Seed M, Kircher C, Willoughby D, Winkler J (1997) The codependence of angiogenesis and chronic inflammation. FASEB J 11:457-465

Jenkins G (2008) The role of proteases in transforming growth factorbeta activation. Int $\mathrm{J}$ Biochem Cell Biol 40:1068-1078

Jimenez B, Volpert OV, Crawford SE, Febbraio M, Silverstein RL, Bouck N (2000) Signals leading to apoptosis-dependent inhibition of neovascularization by thrombospondin-1. Nat Med 6:41-48

Kazerounian S, Yee KO, Lawler J (2008) Thrombospondins in cancer. Cell Mol Life Sci 65:700-712

Kopp HG, Hooper AT, Broekman MJ, Avecilla ST, Petit I, Luo M, Milde T, Ramos CA, Zhang F, Kopp T, Bornstein P, Jin DK, Marcus AJ, Rafii S (2006) Thrombospondins deployed by thrombopoietic cells determine angiogenic switch and extent of revascularization. J Clin Invest 116:3277-3291

Krady MM, Zeng J, Yu J, MacLauchlan S, Skokos EA, Tian W, Bornstein P, Sessa WC, Kyriakides TR (2008) Thrombospondin2 Modulates Extracellular Matrix Remodeling during Physiological Angiogenesis. Am J Pathol 173:879-891

Kyriakides TR, Bornstein P (2003) Matricellular proteins as modulators of wound healing and the foreign body response. Thromb Haemost 90:986-992

Kyriakides TR, Zhu YH, Smith LT, Bain SD, Yang ZT, Lin MT, Danielson KG, Iozzo RV, LaMarca M, McKinney CE, Ginns EI, Bornstein P (1998a) Mice that lack thrombospondin 2 display connective tissue abnormalities that are associated with disordered collagen fibrillogenesis, an increased vascular density, and a bleeding diathesis. J Cell Biol 140:419-430

Kyriakides TR, Zhu YH, Yang Z, Bornstein P (1998b) The distribution of the matricellular protein thrombospondin 2 in tissues of embryonic and adult mice. J Histochem Cytochem 46:1007-1015

Kyriakides TR, Leach KJ, Hoffman AS, Ratner BD, Bornstein P (1999a) Mice that lack the angiogenesis inhibitor, thrombospondin 2 , mount an altered foreign body reaction characterized by increased vascularity. Proc Natl Acad Sci USA 96:4449-4454

Kyriakides TR, Tam JW, Bornstein P (1999b) Accelerated wound healing in mice with a disruption of the thrombospondin 2 gene. J Invest Dermatol 113:782-787

Kyriakides T, Hartzel T, Huynh G, Bornstein P (2001a) Regulation of angiogenesis and matrix remodeling by localized, matrixmediated antisense gene delivery. Mol Ther 3:842-849

Kyriakides TR, Zhu YH, Yang Z, Huynh G, Bornstein P (2001b) Altered extracellular matrix remodeling and angiogenesis in sponge granulomas of thrombospondin 2-null mice. Am J Pathol 159:1255-1262

Kyriakides TR, Rojnuckarin P, Reidy MA, Hankenson KD, Papayannopoulou T, Kaushansky K, Bornstein P (2003) Megakaryocytes require thrombospondin-2 for normal platelet formation and function. Blood 101:3915-3923

Kyriakides TR, Wulsin D, Skokos EA, Fleckman P, Pirrone A, Shipley JM, Senior RM, Bornstein P (2009) Mice that lack matrix metalloproteinase-9 display delayed wound healing associated with delayed reepithelization and disordered collagen fibrillogenesis. Matrix Biol 28:65-73

Lange-Asschenfeldt B, Weninger W, Velasco P, Kyriakides TR, von Andrian UH, Bornstein P, Detmar M (2002) Increased and prolonged inflammation and angiogenesis in delayed-type hypersensitivity reactions elicited in the skin of thrombospondin-2deficient mice. Blood 99:538-545

Lawler J, Sunday M, Thibert V, Duquette M, George EL, Rayburn H, Hynes RO (1998) Thrombospondin-1 is required for normal 
murine pulmonary homeostasis and its absence causes pneumonia. J Clin Invest 101:982-992

Lee S, Jilani SM, Nikolova GV, Carpizo D, Iruela-Arispe ML (2005) Processing of VEGF-A by matrix metalloproteinases regulates bioavailability and vascular patterning in tumors. J Cell Biol 169:681-691

Lin TN, Kim GM, Chen JJ, Cheung WM, He YY, Hsu CY (2003) Differential regulation of thrombospondin-1 and thrombospondin2 after focal cerebral ischemia/reperfusion. Stroke 34:177-186

Lopes N, Gregg D, Vasudevan S, Hassanain H, GoldschmidtClermont P, Kovacic H (2003) Thrombospondin 2 regulates cell proliferation induced by Rac1 redox-dependent signaling. Mol Cell Biol 23:5401-5408

Lorand L, Graham RM (2003) Transglutaminases: crosslinking enzymes with pleiotropic functions. Nat Rev Mol Cell Biol 4:140-156

MacLauchlan S, Skokos EA, Agah A, Zeng J, Tian W, Davidson JM, Bornstein P, Kyriakides TR (2009) Enhanced angiogenesis and reduced contraction in thrombospondin-2-null wounds is associated with increased levels of matrix metalloproteinases-2 and -9 , and soluble VEGF. J Histochem Cytochem 57:301-313

Murphy-Ullrich JE, Poczatek M (2000) Activation of latent TGF-beta by thrombospondin-1: mechanisms and physiology. Cytokine Growth Factor Rev 11:59-69

Oganesian A, Armstrong L, Migliorini M, Strickland D, Bornstein P (2008) Thrombospondins Use the VLDL Receptor and a Nonapoptotic Pathway to Inhibit Cell Division in Microvascular Endothelial Cells. Mol Biol Cell 19:563-571

Page-McCaw A, Ewald AJ, Werb Z (2007) Matrix metalloproteinases and the regulation of tissue remodelling. Nat Rev Mol Cell Biol $8: 221-233$

Puolakkainen PA, Bradshaw AD, Brekken RA, Reed MJ, Kyriakides T, Funk SE, Gooden MD, Vernon RB, Wight TN, Bornstein P, Sage EH (2005) SPARC-thrombospondin-2-double-null mice exhibit enhanced cutaneous wound healing and increased fibrovascular invasion of subcutaneous polyvinyl alcohol sponges. J Histochem Cytochem 53:571-581

Raugi G, Olerud J, Gown A (1987) Thrombospondin in early human wound tissue. J Invest Dermatol 89:551-554

Ribeiro SM, Poczatek M, Schultz-Cherry S, Villain M, Murphy-Ullrich JE (1999) The activation sequence of thrombospondin-1 interacts with the latency-associated peptide to regulate activation of latent transforming growth factor-beta. J Biol Chem 274: 13586-13593

Sakai K, Sumi Y, Muramatsu H, Hata K, Muramatsu T, Ueda M (2003) Thrombospondin-1 promotes fibroblast-mediated collagen gel contraction caused by activation of latent transforming growth factor beta-1. J Dermatol Sci 31:99-109

Schonbeck U, Mach F, Libby P (1998) Generation of biologically active IL1 beta by matrix metalloproteinases: a novel caspase-1-independent pathway of IL-1 beta processing. J Immunol 161:3340-3346

Schultz-Cherry S, Lawler J, Murphy-Ullrich JE (1994) The type 1 repeats of thrombospondin 1 activate latent transforming growth factor-beta. J Biol Chem 269:26783-26788

Schultz-Cherry S, Chen H, Mosher DF, Misenheimer TM, Krutzsch HC, Roberts DD, Murphy-Ullrich JE (1995) Regulation of transforming growth factor-beta activation by discrete sequences of thrombospondin 1. J Biol Chem 270:7304-7310

Simantov R, Febbraio M, Silverstein RL (2005) The antiangiogenic effect of thrombospondin-2 is mediated by CD36 and modulated by histidine-rich glycoprotein. Matrix Biol 24:27-34

Singer AJ, Clark RA (1999) Cutaneous wound healing. N Engl J Med 341:738-746

Streit M, Velasco P, Riccardi L, Spencer L, Brown L, Janes L, LangeAsschenfeldt B, Yano K, Hawighorst T, Iruela-Arispe L, Detmar M (2000) Thrombospondin-1 suppresses wound healing and granulation tissue formation in the skin of transgenic mice. EMBO J 19:3272-3282
Suzuma K, Takagi H, Otani A, Oh H, Honda Y (1999) Expression of thrombospondin-1 in ischemia-induced retinal neovascularization. Am J Pathol 154:343-354

Tang Y, Scheef EA, Wang S, Sorenson CM, Marcus CB, Jefcoate CR, Sheibani N (2009) CYP1B1 expression promotes the proangiogenic phenotype of endothelium through decreased intracellular oxidative stress and thrombospondin-2 expression. Blood 113:744-754

Taraboletti G, Belotti D, Borsotti P, Vergani V, Rusnati M, Presta M, Giavazzi R (1997) The 140-kilodalton antiangiogenic fragment of thrombospondin-1 binds to basic fibroblast growth factor. Cell Growth Differ 8:471-479

Tian W, Kyriakides TR (2009) Thrombospondin 2-null mice display an altered brain foreign body response to polyvinyl alcohol sponge implants. Biomed Mater 4:15010

Uno K, Hayashi H, Kuroki M, Uchida H, Yamauchi Y, Oshima K (2004) Thrombospondin-1 accelerates wound healing of corneal epithelia. Biochem Biophys Res Commun 315:928-934

Velasco P, Huegel R, Brasch J, Schroder JM, Weichenthal M, Stockfleth E, Schwarz T, Lawler J, Detmar M, Lange-Asschenfeldt B (2009) The angiogenesis inhibitor thrombospondin-1 inhibits acute cutaneous hypersensitivity reactions. J Invest Dermatol 129:2022-2030

Wang S, Wu Z, Sorenson CM, Lawler J, Sheibani N (2003) Thrombospondin-1-deficient mice exhibit increased vascular density during retinal vascular development and are less sensitive to hyperoxia-mediated vessel obliteration. Dev Dyn 228:630-642

Yan J, Zeng Y, Zhou J, Yin Z, Wang Z, Zhu P (2007) The expression patterns of vascular endothelial factor and thrombospondin 2 after corneal alkali burn. Colloids Surf B Biointerfaces 60:105-109

Yang Z, Kyriakides TR, Bornstein P (2000) Matricellular proteins as modulators of cell-matrix interactions: adhesive defect in thrombospondin 2-null fibroblasts is a consequence of increased levels of matrix metalloproteinase-2. Mol Biol Cell 11:3353-3364

Yang Z, Strickland DK, Bornstein P (2001) Extracellular matrix metalloproteinase 2 levels are regulated by the low density lipoprotein-related scavenger receptor and thrombospondin 2. J Biol Chem 276:8403-8408

Yano K, Oura H, Detmar M (2002) Targeted overexpression of the angiogenesis inhibitor thrombospondin- 1 in the epidermis of transgenic mice prevents ultraviolet-B-induced angiogenesis and cutaneous photo-damage. J Invest Dermatol 118:800-805

Yano K, Brown L, Lawler J, Miyakawa T, Detmar M (2003) Thrombospondin-1 plays a critical role in the induction of hair follicle involution and vascular regression during the catagen phase. J Invest Dermatol 120:14-19

Yano K, Kajiya K, Ishiwata M, Hong Y, Miyakawa T, Detmar M (2004) Ultraviolet B-induced skin angiogenesis is associated with a switch in the balance of vascular endothelial growth factor and thrombospondin-1 expression. J Invest Dermatol 122:201-208

Yano K, Kadoya K, Kajiya K, Hong Y, Detmar M (2005) Ultraviolet B irradiation of human skin induces an angiogenic switch that is mediated by upregulation of vascular endothelial growth factor and by downregulation of thrombospondin-1. Br J Dermatol 152:115-121

Yee KO, Streit M, Hawighorst T, Detmar M, Lawler J (2004) Expression of the type-1 repeats of thrombospondin-1 inhibits tumor growth through activation of transforming growth factorbeta. Am J Pathol 165:541-552

Young GD, Murphy-Ullrich JE (2004) The tryptophan-rich motifs of the thrombospondin type 1 repeats bind VLAL motifs in the latent transforming growth factor-beta complex. J Biol Chem 279:47633-47642

Zhang X, Lawler J (2007) Thrombospondin-based antiangiogenic therapy. Microvasc Res 74:90-99

Zhu W, Smart EJ (2005) Myristic acid stimulates endothelial nitricoxide synthase in a CD36- and an AMP kinase-dependent manner. J Biol Chem 280:29543-29550 